\title{
Agency, Embodiment, \& Affect During Play in a Mixed-Reality Learning Environment
}

\author{
Danielle Keifert \\ University of California \\ Los Angeles CA, USA \\ keifert@ucla.edu
}

\author{
David DeLiema \\ University of California \\ Berkeley CA, USA \\ deliema@berkeley.edu
}

\author{
Christine Lee \\ University of California \\ Los Angeles CA, USA \\ clee@labschool.ucla.edu
}

\author{
Maggie Dahn \\ University of California \\ Los Angeles CA, USA \\ maggiedahn@gmail.com
}

\author{
Noel Enyedy \\ University of California \\ Los Angeles CA, USA \\ enyedy@gseis.ucla.edu
}

\author{
Joshua Danish \\ Indiana University \\ Bloomington IN, USA \\ jdanish@indiana.edu
}

\begin{abstract}
Beginning from the assumption that young children (ages 68) are capable of reasoning about complex phenomena [12], we set out to better understand dimensions of the Science through Technology Enhanced Play environment that provided support for children to learn about relationships between multiple levels of an emergent phenomenon [23] states of matter. We conducted interactional analysis [15] of several moments in two classrooms as students developed and refined understanding of rules that connect micro behavior of particles of water to macro understanding about states of matter. We argue that central to students' disciplinary work were (1) multiple forms of agency negotiated within the STEP environment that were deeply intertwined with (2) students' embodiment. Agency and embodiment both supported students' consensus understanding of relationships between levels of the states of matter phenomenon (3) through students' joyful and playful collaborative work. We examine several episodes in detail to explore these findings.
\end{abstract}

\section{Author Keywords}

Science learning; early-elementary; mixed-reality; sociodramatic play; agency; embodiment; affect.

\section{ACM Classification Keywords}

K.3.1 [Computers and Education]: Computer Uses in Education - Collaborative learning.

Permission to make digital or hard copies of all or part of this work for personal or classroom use is granted without fee provided that copies are not made or distributed for profit or commercial advantage and that copies bear this notice and the full citation on the first page. Copyrights for components of this work owned by others than ACM must be honored. Abstracting with credit is permitted. To copy otherwise, or republish, to post on servers or to redistribute to lists, requires prior specific permission and/or a fee. Request permissions from Permissions@acm.org.

IDC '17, June 27-30, 2017, Stanford, CA, USA

(C) 2017 Association for Computing Machinery.

ACM ISBN 978-1-4503-4921-5/17/06...\$15.00

http://dx.doi.org/10.1145/3078072.3079731

\section{INTRODUCTION}

Despite a commonly held belief that young children are not ready to engage in complex science learning, scholars have argued that even very young children can grapple with advanced scientific phenomena [12]. Work that engages students with sophisticated concepts pushes against fixed notions of development and opens opportunities for students to learn about advanced science topics such as complex systems of honeybee pollination $[7,8]$, micro properties of states of matter [11], and the very nature of science [1]. We argue that three central aspects of successful learning through play in our context included (1) student agency for directing learning and activity, (2) the role of embodiment in thinking about complex systems, (3) and the centrality of affect for the endeavor of science.

\section{EMBODIMENT, AGENCY, AND POSITIVE AFFECT IN SOCIODRAMATIC PLAY FOR SCIENCE}

These themes of embodiment, agency, and affect have been reflected in prior work on STEM learning. Papert long ago argued for the importance of embodiment in STEM learning [21], and the call to provide opportunities for embodiment continues in work arguing to broaden forms of sense-making recognized as productive for science learning [22]. Within our context of sociodramatic play, we define embodiment as moments when children use their bodies to represent other entities (e.g., water particles). Furthermore, science education literature has emphasized the importance of students taking ownership of their ideas, wrestling with the inquiry process themselves (e.g., [17]). We specifically define agency in the context of embodied sociodramatic play as those moments when children direct their own or other's bodies during embodiment. Students might move around the space as they choose (e.g., running in circles), direct others to create particular patterns (e.g., "Let's make a diamond"), or coordinate together (e.g., "Everybody, hold my hands!"). Additionally, recent work has emphasized the centrality of affect in science. Affect is not merely an issue of motivation, but is central to the disciplinary work of science itself [14]. We are particularly interested in understanding the role of joy, playfulness, and excitement in science learning (though 
we acknowledge feelings of confusion and frustration are equally central to science).

We explore how student agency, embodiment, and positive affect support children becoming legitimate participants in the disciplinary work of science through sociodramatic play. Through a designed learning experience we call STEP (Science through Technology Enhanced Play), we explore students' development of rules relating multiple levels [23] of a scientific phenomenon - states of matter - through a playful, embodied, mixed-reality collaborative simulation.

We begin with a description of the STEP mixed-reality environment including the technology, the interactional space, and the sociodramatic framing of activities. We then present case studies in which students developed and refined rules relating micro-particle behavior to the macro phenomena of creating solids, liquids, or gases. We end by synthesizing our analysis of the STEP environment to better understand the role of agency, embodiment, and affect as central to disciplinary science learning within STEP.

\section{STEP ENVIRONMENT}

STEP is a mixed-reality (MR), body-based, collaborative environment. We view the STEP environment as an enactment of Vygotsky's [25] conceptualization of sociodramatic play, which includes (1) rules, (2) roles, and (3) and an imaginary situation. We believe this approach lends itself to opportunities for students to engage in science through embodiment, thereby supporting young children's understanding of complex systems. Two mixed-age first- and second-grade classrooms (ages 6 through $8 ; n=26$ ) participated in six days of embodied activities in science learning through a collaborative effort between the students and teachers. Students engaged in learning about changes in states of matter for water by embodying both macro, observable characteristics of matter (e.g., solid ice, liquid water) as well as micro, particulate behavior of matter (i.e. solid, liquid, or gas particles).

We focus on two days of activities that included students playing as particles exploring patterns of making solid (white), liquid (blue), and gas (red). Students were tracked through open-source computer vision softwareOpenPTrack [18]. OpenPTrack (OPT) was developed in response to the inception of the STEP research which required markerless person-tracking. The overall goal of the sequence of activities was for students to understand macro and micro properties of states of matter including factors such as how distance and speed impact state change (e.g., particles that vibrate in place and are spaced far away make solid; particles that are slow moving and closely spaced make liquid; particles that are fast moving make gas).

The STEP space (Figure 1) was used when the class was oriented to tracking activity (in contrast to discussion during which students oriented away from the screen towards the teacher and documentation.) The space was designed to foster a collaborative environment that encouraged play as part of the students' learning. This was achieved through a large open space for activities. This configuration allowed students to enter the STEP tracking space and interact with the learning content without the need for markers or other objects to interface with STEP software. Within the STEP tracking space there was a large-format projection screen that was used to visualize the MR environment. In addition to displaying particles, this screen also provided various tools at different points in the lessons. For example, a new tool, the state-meter (Figure 2), was introduced during the second lesson we analyze here. This tool displayed information about the proportion of students in the space that were solid, liquid, or gas at any given time.

During the sociodramatic play in these lessons, students were assigned roles as particles and directors within the imaginary, embodied situation to support their work to determine the rules of behavior for particles at microscopic levels. All students had a chance to perform both roles, which defined how they interacted with each other and the technology. Student particles explored the MR space through their movements in the tracked space, which in turn controlled their particle in the simulation they would see on the projection screen. Student directors sat outside the

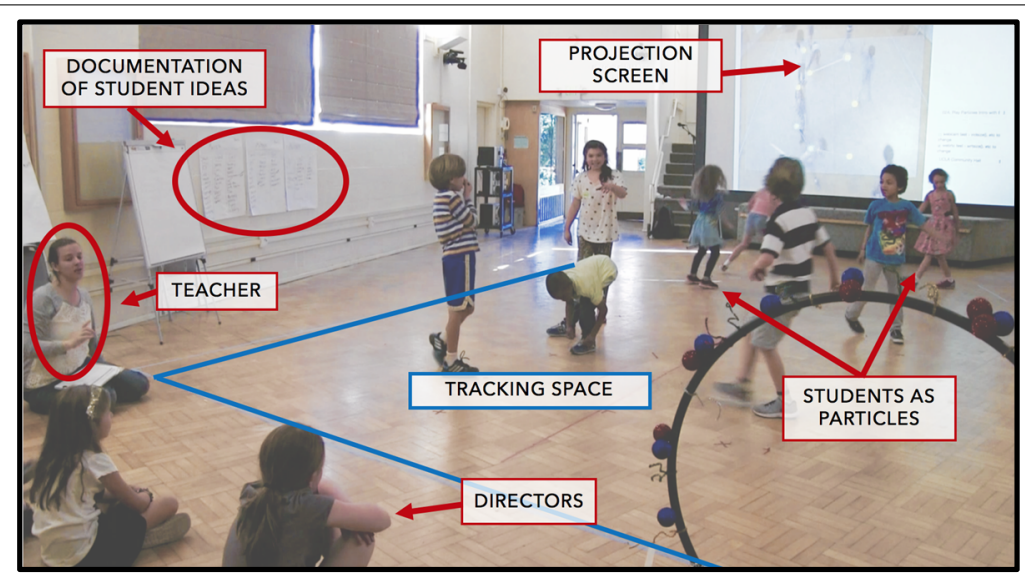

Figure 1. Student directors observe student particles while the teacher sits near prior documentation of student ideas and consensus rules.

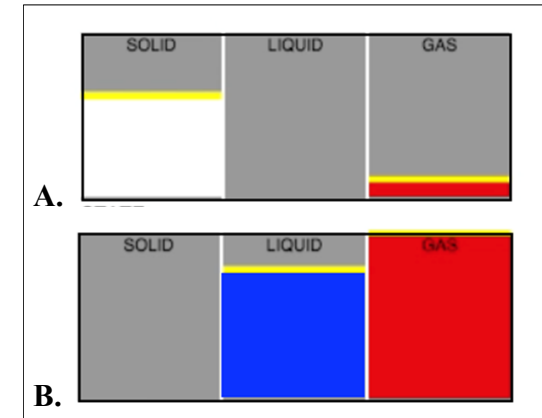

Figure 2. The state-meter displayed proportions of particles in each state. $2 \mathrm{~A}$ shows most particles as solid and a few as gas. 2B shows particles split between liquid and gas. 
tracked area with the goal of looking for emerging patterns in particles' play. Directors gave instructions to particles regarding goals (what state to make) and multiple methods of achieving goals including creating particular kinds of movement (skip, run, stand still), gestures (move arms up and down), or patterns (make a diamond, spread out). These directions came both as students initially developed ideas about the relation between particles' movement and states of matter, as well as a means for refining or retesting consensus rules.

In this paper, we examine how students in both director and particle roles contributed to the development of ideas into consensus rules for explaining relationships between micro particle behavior and states of matter. Students were not initially taught rules that describe states of matter. Instead, students developed their own ideas and consensus rules through playful embodiment, excited observations, and early expressions of their initial learning through gesture [13]. As such, the students' movement became a crucial factor in their body-based learning [16] and interactions. Also critical to this work were daily reflections in the discussion space during which students worked with teachers to create a written list-documentation - of the observed rules in the particle simulation. These rules were referred back to, changed, and modified throughout the STEP activities as students learned together.

\section{METHODS}

\section{The Lessons}

Our STEP curriculum included both macroscopic and microscopic lessons on state changes of water particles (solid, liquid, and gas). Macroscopic lessons included observable characteristics of water such as associating cold temperatures with ice. Our microscopic lessons included particle behavior in each state of matter (solid, liquid, gas) as well as how energy impacts changes in states of matter. For this case study, we examine two lessons in two different classrooms (lead by different teachers) that covered microscopic particle behavior for each state of matter. We focused on these two lessons because we wanted to trace students' work to move from observations to expressed ideas and finally to consensus rules relating micro particle behavior to macro states of matter.

We looked for ideas that became consensus rules through embodied inquiry of particles, the directions provided by directors, and discussions with teachers. The goal of the two lessons was to learn how to make each state of matter in the particulate level according to speed and/or distance (e.g. to make gas, particles must move quickly in the space). During the first lesson, both classrooms developed initial ideas and created documentation on how to make a certain color with their bodies. During the second lesson, the goals were to test existing ideas and develop consensus rules. Across these two lessons we traced all student ideas on how to create white (solid) in one classroom, and we traced student ideas on how to create blue (liquid) in the other classroom. For each we provide a detailed sequence of episodes, and then examine a few moments more closely.

\section{Analysis Process}

Following the identification of these episodes, we analyzed each following the tradition of Interaction Analysis [15]. This included creating transcripts, analyzing each line-byline, characterizing each turn, and developing an understanding of patterns across episodes. In this paper, we focus on moments within the last of the episodes in both classrooms. We chose these episodes because they afforded us an opportunity to explore particular forms of agency within the STEP play space, demonstrated the importance of collaborative action during particles' embodiment, and presented different examples of the centrality of positive affect to the work of scientific inquiry. Using these episodes we ask: How did the STEP environment support students' work to develop consensus rules for particle behavior through playful embodied exploration and discussions? In what follows, we argue that central to the how of the above question were opportunities for agency, embodiment, and positive affect afforded in the STEP environment.

\section{ANALYSIS}

\section{Solid White}

We begin presenting analysis of the last episode in the sequence of student inquiries about how to make white (solid) from one classroom (Figure 3). In these episodes students developed the idea that standing still or jumping in place would "make white," and over time began to accept this as a consensus rule. In the last episode, there was a shift

Teacher guides standing in a circle and spreading out. A student notes that distance between people and "standing still" relate to making white.

Teacher asks student to observe what particles are doing in the space. Students note distance between people and "standing still" relate to making white.

Students observe "standing still" as a particle makes white. The teacher documents the observation.

Students notice and warn others that running in place makes white. The teacher documents the observation

A student states if you jump up and down in place, you still turn white "because we're just in place".

A student notices the state-meter. Students begin to use "solid liquid gas" language instead of colors. A

student connects the rule of standing still to making solid (not white).

Figure 3. Episodes during which students discussed how to make white or solid in STEP. Purple borders represent Day 2 activities, Orange borders day 3 activities. Shaded box is the episode analyzed here. 


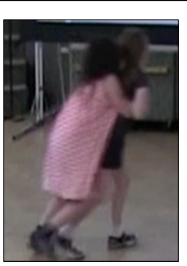

Figure 4. Bethany and Sarah move in a particle-hug.

1 Brandon: .hhh Hey! (That says solid and liqu::id)

Brandon points to screen turns to Ms. Jones.

2 Brandon taps Ms. Jones with left hand.

3 Ms. Jones leans towards Brandon, sets her hand on his shoulder.

4 Ms. Jones: What?

Ms. Jones lifts her hand off of Brandon's

shoulder and points towards the screen.

5 Brandon turns to face the screen, still pointing.

6 Ms. Jones: Tell them Brandon!

Ms. Jones raises her arms and then drops in quickly as she shouts to Brandon.

7 Brandon: GUYS EVERYBODY, LOOK AT THAT!!

Figure 5. Brandon shows the state-meter to Ms. Jones and she encourages him to share.

in their language from "making white" to "making solid" accompanied by the introduction of a new tool. We explore how agency was enacted both through (a) the roles assigned within the sociodramatic play of the STEP environment, as well as through (b) the positioning of students by teachers (or other adults, e.g., researchers) with regard to agency. We also examine how the introduction of the new tool (state-meter) shaped students' language and embodiment, and as a result impacted students' evolving goals. Finally, we examine the role of positive affect in this particular moment, as it runs central to the activity shaped by this tool.

Introduction of the state-meter: "Everybody look at that!" Students in classroom one had been exploring how to make patterns related to the particle color; students focused on making white (or red, or blue) prior to this moment. In the midst of the particles' free exploration, a researcher turned on a new tool: the state-meter.

Within 10 seconds, students' interactions demonstrated they had noticed it. Bethany, a particle, pointed it out to another particle, Sarah. Bethany and Sarah had been moving in a particle hug - a formation where students stand close to each other or hug one another (Figure 4), causing STEP to track them as one body and therefore one particle. After the introduction of the state-meter, Bethany broke the hug, pointed it out to Sarah, and both girls moved closer to the screen. At nearly the same time, a director, Brandon, pointed out the state-meter to his teacher. Brandon's excitement was evident as he turned around to his teacher, Ms. Jones (Figure 5). Brandon described what he saw, "Hey, that says solid and liquid" to which Ms. Jones responded with an excited "What?!" and then shouted, "Tell them, Brandon!" lifting her arm before dramatically dropping it. Brandon jumped up and shouted, "Everybody, look at that!" and ran into the tracking space pointing at the state-meter, before returning to his spot to watch the particles respond.

These three students' actions in this short span of 20 seconds display two distinct forms of agency in the STEP play environment. First, Bethany and Sarah were demonstrating their own agency in determining how to move in the space as particles. Bethany and Sarah chose to take advantage of the exploratory time, where no directors had told them how to act, and made the particle-hug arrangement against the advice of researchers who were concerned with each student being tracked separately at all times. Brandon, on the other hand, took advantage of another form of agency when he received encouragement directly from his teacher to direct particles in the space. As a director, Brandon was already positioned to direct particles' actions. However, the offer from his teacher provided Brandon with the push to shift the pattern of activity in the environment away from exploratory play, which we discuss next.

These forms of agency - of particles to direct their own activity during exploratory play, directors directing particles' activity, and specific encouragement from adults-provided opportunities for students to direct their own and each other's embodied activity. We recognize both roles in the context of sociodramatic play, particles and directors, and the specific offers of agency from adults could enable or constrain individuals' agency. For instance, the particles' agency over their own embodiment shifted as the class moved from exploratory play of particles, where particles could selfdirect their activity, to the testing of a particular rule, where a director, Brandon, determined particles' activity.

After Brandon returned to stand by other directors, Samantha, another director, turned to Ms. Jones. Although

1 Brandon: GUYS YOU NEED TO MAKE SOLID! and you're gonna stay still!

2 Leon pivots and begins to run around the space moving in a big circle. Lilly begins to run in a smaller circle.

4 Bethany stretches out her left leg stamping down in an spread leg formation stretching her arms out, making a large $X$ with her body. She holds that position steady.

5 Leon: Make gas

6 Sarah turns partially to face Leon, lifting her arms up in front of her making a "stop" motion.

7 (student): Stay still for a second

8 Sarah: Stay still! (unclear) stay still! Sarah steps to the side as Leon approaches her, spreading her arms out.

9 Sarah steps towards Leon.

10 Leon stops and faces the screen. Bethany drops one arm and raises the other straight up.

11 (student): (don't) mo:::ve

12 (student): Stay still

13 (student): Stay still

14 Lilly stops, leans forward stretching her arms about behind her.

Figure 6. Brandon directs particles and they respond. 
Samantha's talk is not audible, Ms. Jones clearly said to Samantha "Okay, tell them that, and tell them what they need to do". Ms. Jones' comment suggested a particular form that direction should take-direct particles what state to make and how, or by what method to make it. In the subsequent turn, Brandon did just that (Figure 6). Brandon shouted "Guys, you need to make solid, and you're gonna stay still!" following the format Ms. Jones indicated to Samantha. In response, most particles shifted to standing still, and those few that didn't were quickly reined in by other particles (particularly Sarah as she shouted "Stand still" and spread her arms out to block Leon from continuing to run). Two things are of particular note here.

First, students' language shifted from prior talk about making white, blue, or red to a consistent language of making solid, liquid, or gas. In this classroom, the shift occurred directly after the introduction of the state-meter by Brandon to the rest of the class, and was adopted by all students. This minor shift in language indicates a significant contribution to the development of a consensus rule through which students mapped their embodied activity as particles to resulting states of matter. Through this shift in language, students directly tied movement of particles at one level to emergent states of matter at another. This was a central goal of these two lessons.

Second, there was a shift in agency and embodiment as a result of Brandon's direction. Prior to his direction to "make solid" and "stay still", particles were engaged in free exploratory play as they self-directed their own activity. Following his utterance, particles who had been embodying several small and independent patterns organized together to collectively stand still to make solid. Particles were involved in this shift in agency by allowing directors to direct as they disciplined their own and each other's bodies to collectively make white by standing still. As a result, Brandon's direction led to a testing of a prior consensus rule that standing still makes white within the context of the new language introduced by the state-meter, testing instead if standing still makes solid. Thus, shifts in agency, language, and embodiment were tied together. Specifically, they were all critical in students' work to link colors of particles to states of matter, reflecting students' development of a shared understanding of the relationship between particle motion and color (standing still to make white) and the resulting state of matter (making solid), and meeting the central goal of these lessons.

Additionally, this moment illustrates the centrality of positive affect, particularly excitement. Brandon's excitement was evident as he quickly turned around and shared his noticing of the state-meter with Ms. Jones, who in turn demonstrated her own excitement as she enthusiastically replied "What?!" and then "Tell them, Brandon!" The cascade of excitement continued as Brandon shouted and ran into the space to point out the state-meter to other students, and several moved forward to take note of the state-meter. In
1 Leon: Liquid, solid Leon drops his arm and turns to face directors.

2 Kara skips the other way and forward towards the students.

3 Zach skips towards the cluster of students near the statemeter.

4 (Carl?): Oh yeah

5 Leon turns back towards screen and moves closer to statemeter side.

6 Leon raises her arm and points to state-meter again.

7 Leon: That's gas, liquid, and solid

Leon points to each of the bars on the state-meter.

8 Kara moves away from Lilly, bouncing towards the screen.

9 Leon walks away from the screen

Figure 7. Leon reads and points to the states twice, other particles move towards him.

addition to Bethany and Sarah who had already moved closer to the screen to inspect the state-meter, Leon ran from having his shoe tied by a researcher to standing immediately next to the screen and pointing out each of the states on the statemeter (Figure 7). Leon's excitement was evidenced by his running and his quick (and loud) repetitions of reading each of the states while pointing to their bar on the state-meter.

Other students, too, showed evidence of excitement; another director, Carl, stood up at the same time as Brandon and said "Oh Yeah!", several particles shifted their bodies from motion towards standing close to the screen to inspect, and particles shifted into collaborative patterns in response to Brandon's later direction. We argue this cascade of excitement, starting with Brandon and moving through Ms. Jones, Leon, and other students (both directors and particles), was central to the discovery of the state-meter and the shift from free exportation of particles into the collective testing of a consensus rule. By this we mean that the excitement of the state-meter led directly to the collaborative effort to tie their prior rule (standing still makes white) to the new language of the state-meter (standing still makes solid) thus creating a critical link for students between embodied action, color of particles, and state of matter created. Essentially, agency, embodiment, and affect were deeply intertwined in students' successful elaboration of a consensus rule to capture the disciplinary idea of relating particle behavior to states of matter.

\section{Liquid Blue}

In the second classroom, we analyzed the development of creating liquid (blue). We examined the development of an idea about a pattern - holding hands while walking slowly in a circle - as it developed over two days into a consensus rule for making blue (Figure 8). We found contrasts to the previous episode in how the technology was used and how teacher and student roles played out. In this sequence, the state-meter had already been introduced by the teacher during a discussion. Although there was no excitement of discovery of the state-meter as in the prior classroom, the students in this classroom used the state-meter as a tool for 


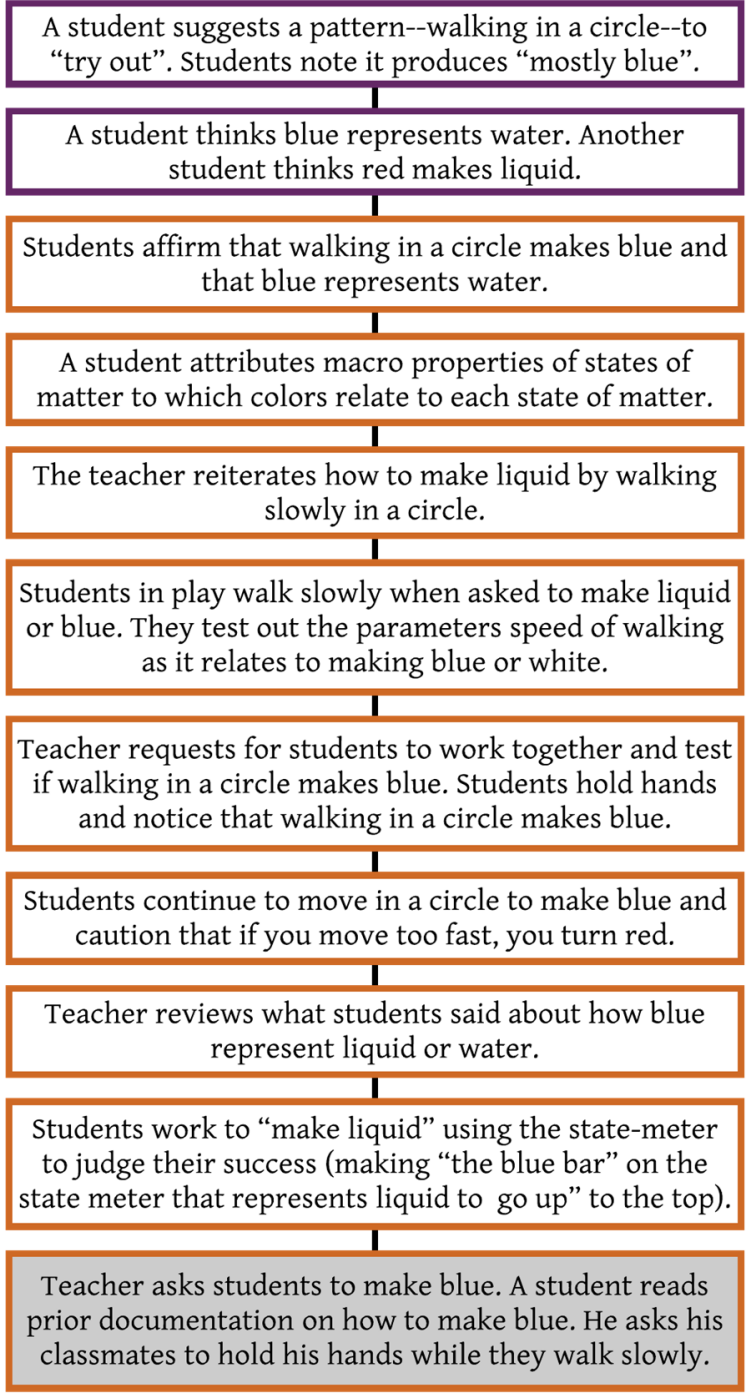

Figure 8. Episodes during which students discussed how to make liquid or blue. Purple borders represent Day 2 activities, Orange borders day 3 activities. Shaded box is the episode analyzed here.

measuring success in creating liquid, impacting collaborative activity. We also found a shift in the roles for teacher and students; all students were assigned the role of particles. With no student directors, we saw more fluid agency in the space. The lack of student directors also led to more consistent playful, exploratory moments rather than testing of an established consensus rule, as well as searches by students for sources of authority to direct each other.

We explore two moments within this episode in closer detail: first, a moment in which a student made use of prior documentation to take agency in directing other particles to make liquid, and second, a moment of playful exploration in which the state-meter served as a tool that rallied support for collaborative action.
1 David (researcher): What do you think we could try to make [it more blue?

2 Ms. Bell: What could we do?

3 Ms. Bell: What did you guys recommend?

4 Jesse leaves the space

5 (student): Regular [walking!

6 Jesse comes back into the space

7 Jesse: [walking in a circle

8 Ms. Bell: Regular walking, and

9 Jesse walks towards students and holds his arms out.

10 Jesse: Hold! my hands everybody!

11 David: You're doing a pretty good job, there's a lot of liquid.

Figure 9. Jesse seeks documentation and then directs.

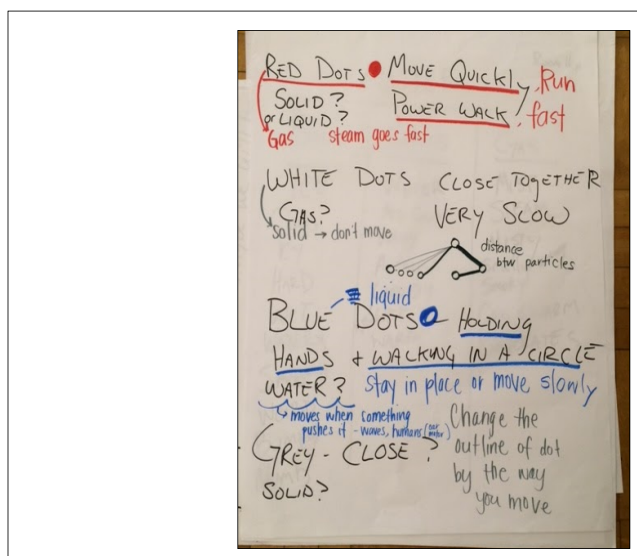

Figure 10. Documentation from Ms. Bell's classroom.
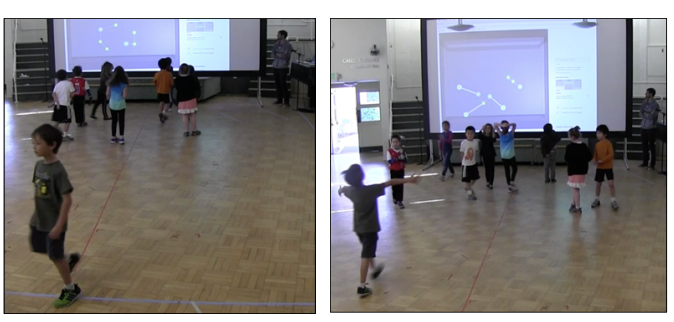

Figure 11. Jesse walks out of the tracking space to check documentation, then returns with his arms out.

Checking documentation to provide direction: "Everybody hold my hands!"

Class documentation was a source of agency and authority. In this episode, a student drew upon this documentation to take agency in directing other particles to make liquid (Figure 9). All students were acting as particles, and only the teacher and researchers remained outside the tracking space. At the start, the teacher and researcher (David) provided a suggestion to think about past methods used to create liquid (lines $1 \& 2$ ). Shortly after, a student responded by leaving the tracking space to reference the recorded documentation from the prior day's work.

As other students continued their free exploration of how to make liquid, Jesse walked out of the space to the back of the room (line 4) to review the documentation of rules for making liquid. The documentation (Figure 10) included 
notes on holding hands and walking in a circle (underlined in blue) as it related to blue dots, and later a notation that these might be liquid (added in blue marker). In Figure 11, we see Jesse walking away from his peers towards the back of the room. After reading the documentation, Jesse returned to the tracking space holding his arms wide open, and shouting "Hold! My hands everybody!" In this sequence, the documentation at the back of the room provided Jesse with a sense of agency in that he checked for a consensus rule for making liquid. His adoption of agency is demonstrated through his directive statement in line 11.

Although Jesse left the tracking space, he continued to play his role as a particle throughout the sequence; rather than asking his peers to hold hands, he requested that everybody should hold $m y$ hands and held his hands out to others. Thus, Jesse continued to embody a water particle and never switched his role to a director (as might have been evident if he had said "everybody hold hands" and didn't extend his own hands to take part). In contrast, the first classroom had students take on the role of a director, which influenced how students playing as particles acted in the tracking space. However, due to the lack of student directors in this class, Jesse took the agency to help organize the activity for the particles. The work to direct each other's actions as particles also took other forms during another moment in the same episode of trying to make liquid.

Collaborative action growing from playful exploration: "Guys, squeeze together and pretend like we're a particle."

Within the same episode, as students experimented with how to create liquid they considered a range of possibilities, one of which was to squeeze together in what we call a "particle hug". The transcript (Figure 12) details how the particle hug unfolded. In lines 1 and 2 two students solicited the attention of others by presenting an idea to all "squeeze together". Initially the students engaged in this playful hug to try to make one dot as a group, however, in line 4 Kay suggested that squeezing together to make one particle made it easier

1 (student): Guys, squeeze together and pretend like we're a particle

2 (student): Squoosh in together and we'll all be a particle

3 Particles move close to each other. Three students are hugging.

4 Kay: Then it will be easier to create a blue.

5 Sam joins the particle hug.

6 Teacher: Is it? (.) are you- look at the meter, is that working to create a blue.

7 David joins the particle hug.

8 Jesse: Yeah it is! Guys, squoosh in

9 Jesse glances back at Nico then joins the particle hug

10 Adam and Drew join the hug.

11 Students make "squeezing" noises

12 ?: There's still three dots

13 Ms. Bell: ((laughing))

14 (student): Ha!

15 Researcher: ((laughing))

16 Students break particle hug.

Figure 12. Transcript of the particle-hug. to "create a blue". Perhaps because Kay's claim was aligned with their present task, more students joined in the collective action.

In line 6 the teacher suggested that students look at the statemeter to confirm or disprove that their strategy was successful in making blue. In line 8 Jesse, a new student who had not yet joined the particle-hug, used the state-meter to affirm the hug was working to create blue. By line 10, all students joined together in coordinated action and embodiment of the particle hug.

In the particle hug, during a time when no students were taking on the role of director, agency was distributed among students playing as particles; no one student directed all others into the hug method. Rather, a series of moments led to a growing collaboration so the entire class could participate in the collective action. The images in Figure 13 show how the embodiment of the particle hug progressed from a few students experimenting and taking part to the entire group participating in the hug after it was affirmed that the hug was "working" to create liquid.

Within the particle hug the state-meter encouraged collaborative, playful testing and was used as a tool for supporting Kay's claim that by making fewer particles it might be easier to make liquid particles. Because students were only given the goal of the state to make they had the agency to try out different possibilities for how to achieve the goal using the state-meter as a gauge of their success.

While the teacher in the "making white" examples described in the previous section asked the directors on the perimeter of the tracked space to tell students playing as particles what to make and how to make it, the teacher guiding the particle hug episode only suggested what to make and did not ask for students to predetermine a strategy for how to make it. Due to this ambiguity of method, and a lack of students in the director role, students activated their own agency as they collectively decided how to achieve the desired state. Students had to self-organize by conducting exploratory testing with their bodies in relation to the STEP technology. The state-meter was a critical tool because it verified the particle hugging method to students who did not initially join, ' leading to a growing collaboration that led to all students participating in the particle hug (Figure 13).

However, although the state-meter was used as a tool to affirm their method, it is questionable as to whether or not students achieved their goals. In line 8 of the transcript above Jesse asserts that their method was successful, although it is unclear as to whether or not this was a group consensus. The initial goal of the particle hug was to make one particle, and according to a student in line 12, there were "still three dots", leaving them short of the initial goal.

It is interesting to note that student agency in this episode included push back against the teacher's guidance. When the teacher asked students, "Is it?" in line 6 (Figure 12) and directed them to use the state-meter to evaluate the 
effectiveness of their collective action, her tone implied that the particle hug method would not be successful for making liquid. However, students continued to hug and the teacher allowed them to pursue their inquiry without intervening.

Additionally, students were clearly enjoying themselves and showing a positive affective response as they engaged in testing the particle hug. The adults also showed positive affective responses despite the teacher's implied desire for students to try something else. At the moment when all students squeezed together both the teacher and a researcher laughed. This is particularly interesting because there is a school-wide rule for students to keep a "bubble" around them at all times so they learn to respect one another's personal space, yet the particle hug moment violated this rule, even as both adults and students found joy in doing so. This joyfulness and silliness, embraced by students, teacher, and researchers, suggests a recognition in the STEP space of the importance of exploratory embodied play in students' work to develop understanding of science disciplinary ideas.

\section{DISCUSSION}

Across these episodes, several possibilities opened for students' science learning through the context of sociodramatic play in the STEP environment. Play offered a productive context for students' scientific disciplinary work just as it does for scientists in their professional endeavors [4]. Sociodramatic roles allowed for shifting opportunities for observing, directing (directors), and embodying (particles) as students developed and refined their understanding of the relationship between the microbehavior of water particles at one level and macro states of matter (solid, liquid, gas) at the emergent level. We traced students' ideas about these relations as they excitedly tested (and retested) those rules using STEP technology (e.g., tracking, project, and tools like the state-meter) and defined their own markers of success (e.g., making lots of liquid, becoming one particle) while engaged in playful exploration (e.g., particle hug). We argue that central to students' disciplinary work were (1) multiple forms of agency negotiated within the STEP environment that were deeply intertwined with (2) students' embodiment. Agency and embodiment both supported students' consensus understanding of relationships between levels of the states of matter phenomenon (3) through their joyful and playful collaborative work. Although we see these three as intricately interwoven in the success of students' disciplinary work, we begin by examining each in (relative) isolation before articulating their interrelationships.

\section{Agency}

We found that the STEP environment supported multiple forms of agency for students and that agency was embodied in a most essential way-through students directing their own bodies and the bodies of others in playful activity. We believe that student agency is critical to all learning environments, but especially play-based simulations (see [2] for a deep reflection on this topic). The agency that students were afforded in STEP was evident in (a) discipline-specific roles in sociodramatic play as when Brandon exercised his duties as director and told students "Guys you need to make solid! And you're gonna stay still!"; (b) offers and encouragement from teachers such as when Ms. Jones shouted "Tell them Brandon!"; (c) and sources of authority within the STEP environment such as Jesse walking out of the space to consult prior documentation before returning and saying "Hold! my hands everybody!" As students directed others, whether as directors (Brandon) or as particles (Jesse) they articulated both the what and how of emergent goals. By what we mean what state of matter they were attempting to create together (all blue, all solid). By how we mean what each individual should do with their body (stand still) as well as how they should be in relation to others (hold hands, make a particle hug). Essentially, student direction in these episodes articulated understanding about the rules relating students' embodied behavior as particles at one level to the creation of goal states of matter at the emergent level.

It is important to note the collaborative nature of directors and particles working together. For example, student particles enacted their own agency in deciding how to respond to Brandon's suggestion, and worked to enlist the collaboration of their fellow particles (e.g., Sarah working to bring Leon into the fold). We view this collective agency as an embodied negotiation between student particles and student directors, constrained by the roles of sociodramatic play, but nonetheless requiring interactional negotiations. While this definition of agency, either from the perspective of directors or collaborative particle behavior, is relatively narrow (c.f. [3]), we believe that recognizing the importance of agency in directing bodies is particularly important in the playful embodiment central to learning in the STEP environment.

\section{Embodiment}

Embodiment was central to the disciplinary science work in the STEP environment. Regardless of students' roles in any given moment (directors, particles, or even just students), consensus rules were defined through the embodied perspective of particles. In addition to the above moments, students developed rules for individual and collective action such as jumping in place and spreading out to make white, and holding hands and walking slowly in a circle to make liquid. These rules in turn were the central means by which students understood micro-to-macro relations between particle behavior and states of matter; that is to say, students' personal experiences embodying particles provided a basis for reasoning about relations between multiple levels of the emergent phenomenon of states of matter. Additionally, moments like the particle-hug indicate the ways that students drew upon the MR environment to reify their ongoing imaginative embodiment as particles in critical ways. Reasoning with the body from a first-person perspective has proven powerful in science contexts [20] and out of science contexts [18], in part for the same reason that the body 
functioned as such a powerful resource in STEP. Using the body both nudges students automatically toward involvement in the learning process and allows students to see themselves as agents within the focal concept. Additionally, the STEP technology, OPT and the simulation, were designed specifically to allow for embodiment through technological interventions $[9,10]$ to take place within the whole of the STEP environment creating a space for embodiment of the scientific content.

\section{Positive Affect}

Positive affect was equally central to students' work in these episodes, not only for motivation, but also for the endeavor of doing science itself. While acting as a director, Brandon's discovery of the state-meter led to a cascade of excitement throughout the class. The excitement of noticing the statemeter was not only shared with Brandon's peers, but encouraged through the teacher's enthusiastic urge to share in his discovery. This excitement spread among the rest of the class and ultimately shifted from free exploration by particles to testing of a consensus rule. The excitement of the state-meter discovery led directly to the excitement of collaborative activity to explore the scientific phenomena of making solid. In the instance of the particle hug, even though students are violating one of the first rules of making the STEP system work as intended (standing far enough apart so each person appears as a particle on the screen), and despite the fact that the teacher indicates doubts about the productivity of this particular method for achieving the goal of liquid, students, teacher, and researchers all demonstrably shared in the joyfulness of students' work. Students were free to continue to direct their own activity (continued to have agency) as all parties enjoyed their work. These findings align well with recent work exploring the joy in discovering, experiencing, and exploring phenomena in science learning [14], and suggest the need for further work to better understand the interrelations between agency, embodiment, affect, and the disciplinary work of science learning.

\section{Agency, Embodiment, \& Affect in Disciplinary Work}

Although the Framework for K-12 Science Education [6] does not suggest first and second grade students should learn about the relationship between particle behavior and states of matter, we found that STEP supported students to develop rules that accurately represented science understanding about this emergent phenomenon. In trying to better understand why students in these classrooms were able to develop understanding of this complex phenomenon, we found agency, embodiment, and affect were interwoven. In the same way that Cultural-Historical Activity Theorists [4] view cultural systems as an interconnected web of relations between goals, tools, rules, etc., we similarly view students' routes toward learning as inseparable from the specific combinations of agency, embodiment, and affect that arose during their participation in STEP. Students' ideas developed as they directed their own embodied investigations, investigations that led to an embodied understanding of themselves as particles creating the emergent phenomenon of particular states of matter through joyful and playful activity.

\section{CONNECTED WORK}

In future iterations of the STEP environment, we plan to support even more students (up to 24) playing a variety of roles as they draw upon gesture, props, and other forms of environmental variables afforded by person-tracking, bodybased interactivity, and other external variables that can be used to manipulate the digital simulation. We intend to explore how students' ability to manipulate the interplay between their bodies, the physical environment, and the digital environment supports multiple phases of inquiry. We also plan to expand upon this technology to explore not only other domains in science, but also social systems domains (e.g., character education), and the arts (e.g., body-based digital painting). Throughout this work, we would like to explore the relationship between the ideas of agency presented here, focused on ability to direct your own and others' bodies, with broader notions of agency (e.g., [3]), particularly in regards to young students' agency. We also wonder within this work what it means to create a space for students to engage in exploration that is playful, even when adults are concerned about meeting learning goals. We believe play is an ideal medium for supporting disciplinary work in science and other domains and are committed to supporting teachers to expand their notions of its role in learning settings. "If the professions that value creativity and innovation emphasize the need for workers who can use playful ways to be creative" then we must draw upon this as a resource for disciplinary learning in those fields [4:423].

The ideas presented here can be drawn upon for any designed settings that wish to support playful, collaborative, embodied, and agentic learner activity. The combination of the technology that supports the mixed-reality environment and the frame of play promotes (1) drawing upon imaginative scenarios to support students' joyful affect; (2) exploration of ideas for which interactions between entities (people, particles, etc.) are central, including interacting through talk, gesture, gaze, and movement; (3) leveraging bodies to enhance role playing experiences and to position students' bodies as central sensemaking resources for disciplinary ideas; and (4) supporting students' development of their own questions for exploring domain ideas.

\section{ACKNOWLEDGEMENTS}

We would like to thank the students and teachers who participated in the STEP project, as well as members of the broader STEP team whose efforts have been, and continue to be central to the success of the project. In particular, Asmalina Saleh and Megan Humburg, of Indiana University, Matteo Munaro, Marco Carraro, and Jeff Burke the UCLA OpenPTrack team, and Ben Loh and David Seah at Iquirium. We also wish to acknowledge support from the National Science Foundation (DRL-0733218, IIS-1522945, IIS1628918, and IIS-1323767). 


\section{REFERENCES}

1. Valarie L. Akerson, Gayle A. Buck, Lisa A. Donnelly, Vanashri Nargund-Joshi, and Ingrid S. Weiland. 2011. The Importance of Teaching and Learning Nature of Science in the Early Childhood Years. Journal of Science Education and Technology 20, 5: 537-549. https://doi.org/10.1007/s10956-011-9312-5

2. Sasha A. Barab, Tyler Dodge, Adam Ingram-Goble, Patrick Pettyjohn, Kylie Peppler, Charlene Volk, and Maria Solomou. 2010. Pedagogical Dramas and Transformational Play: Narratively Rich Games for Learning. Mind, Culture, and Activity 17, 3: 235-264. https://doi.org/10.1080/10749030903437228

3. Angela Calabrese Barton and Edna Tan. 2010. We Be Burnin'! Agency, Identity, and Science Learning. Journal of the Learning Sciences 19, 2: 187-229. https://doi.org/10.1080/10508400903530044

4. Doris Bergen. 2009. Play as the Learning Medium for Future Scientists, Mathematicians, and Engineers. American Journal of Play 1, 4: 413-428.

5. Michael Cole and Yrjo Engeström. 1993. A culturalhistorical approach to distributed cognition. In Psychological and educational considerations. Cambridge University Press, Cambridge UK, 1-46.

6. National Research Council, Division of Behavioral and Social Sciences and Education, Board on Science Education, and Committee on a Conceptual Framework for New K.-12 Science Education Standards. 2012. A Framework for K-12 Science Education: Practices, Crosscutting Concepts, and Core Ideas. National Academies Press.

7. Joshua A. Danish, Kylie Peppler, David Phelps, and DiAnna Washington. 2011. Life in the Hive: Supporting Inquiry into Complexity Within the Zone of Proximal Development. Journal of Science Education and Technology 20, 5: 454-467. https://doi.org/10.1007/s10956-011-9313-4

8. Joshua Danish, Noel Enyedy, Asmalina Saleh, Megan Humburg, David DeLiema, Maggie Dahn, and Christine Lee. 2017. STEP-Bees: Coordinating embodied interaction with peers, teachers, and computer simulation to support learning.

9. Paul Dourish. 2003. What we talk about when we talk about context. Personal and Ubiquitous Computing 8, 1: 19-30. https://doi.org/10.1007/s00779-003-0253-8

10. Paul Dourish. 2004. Where the Action is: The Foundations of Embodied Interaction. MIT Press.

11. Noel Enyedy, Lee, David DeLiema, Joshua Danish, Asmalina Saleh, Dahn, Kelly Peters, Noelani Morris, Carla-Anne Thomas, Jacqueline Torres, Gabriela Cardenas, Cynthia Creek, Michael Love, Jeff Burke, Randy Illum, Fabian Wagmister, Alex Horn, Matteo Munaro, and Radu Rusu. 2016. Learning About States of Matter Through Multiple Correspondences Among the Body, Abstractions, and Reality.

12. Haim Eshach. 2011. Science for Young Children: A New Frontier for Science Education. Journal of
Science Education and Technology 20, 5: 435. https://doi.org/10.1007/s10956-011-9324-1

13. Susan Goldin-Meadow. 2004. Gesture's Role in the Learning Process. Theory Into Practice 43, 4: 314 321. https://doi.org/10.1207/s15430421tip4304_10

14. Lama Z. Jaber and David Hammer. 2016. Learning to feel like a scientist. Science Education 100, 2: 189220.

15. Brigitte Jordan and Austin Henderson. 1995. Interaction Analysis: Foundations and Practice. The Journal of the Learning Sciences 4, 1: 39-103.

16. Leilah Lyons, Brian Slattery, Priscilla Jimenez, Brenda Lopez, and Tom Moher. 2012. Don't forget about the sweat: effortful embodied interaction in support of learning. In Proceedings of the Sixth International Conference on Tangible, Embedded and Embodied Interaction, 77-84.

17. Eve Manz. 2015. Resistance and the Development of scientific practice: Designing the mangle into science instruction.pdf. Cognition and Instruction 32, 2: 89124.

18. Matteo Munaro, Alex Horn, Randy Illum, Jeff Burke, and Radu Rusu. 2014. OpenPTrack: People Tracking for Heterogeneous Networks of Color-Depth Cameras. In IAS-13 Workshop, 235-247.

19. Ricardo Nemirovsky, Cornelia Tierney, and Tracey Wright. 1998. Body Motion and Graphing. Cognition and Instruction 16, 2: 119-172. https://doi.org/10.1207/s1532690xci1602_1

20. Elinor Ochs, Patrick Gonzales, and Sally Jacoby. 1996. "When I come down I'm in the domain state":

Grammar and graphic representation in the interpretive activity of physicists. In Interaction and grammar, Elinor Ochs, Emanuel A. Schegloff and Sandar A. Thompson (eds.). Cambridge University Press, Cambridge, UK.

21. Seymour Papert. 1980. Mindstorms: Children, Computers, and Powerful Ideas. Basic Books, Inc., New York, NY, USA.

22. Beth Warren, Cynthia Ballenger, Mark Ogonowski, Ann S. Rosebery, and Josiane Hudicourt-Barnes. 2001. Rethinking diversity in learning science: The logic of everyday sense-making. Journal of Research in Science Teaching 38, 5: 529-552. https://doi.org/10.1002/tea.1017

23. Uri Wilensky and Mitchel Resnick. 1999. Thinking in Levels: A Dynamic Systems Approach to Making Sense of the World. Journal of Science Education and Technology 8, 1: 3-19. https://doi.org/10.1023/A:1009421303064

24. Fisher Hirsh-Pasek Golinkoff (2010) Playing around in school- implications for learning and educational policy.pdf.

25. L. S. Vygotsky. 1978. Mind in Society: Development of Higher Psychological Processes. Harvard University Press. 